\section{A Cognitive-affective Model of Relational Expectations in the Provider-patient Context}

\author{
DAN O'HAIR \\ University of Oklahoma
}

JOYCE ALLMAN

Texas Christian University

SCOTT D. MOORE

University of Oklahoma

DAN O'HAIR is Professor and Chair in the Department of Communication at the University of Oklahoma.

JOYCE ALLMAN is Assistant Professor in the Department of Speech Communication at Texas Christian University.

SCOTT D. MOORE is a Graduate Research Assistant in the Department of Communication at the University of Oklahoma.
Journal of Health Psychology Copyright (C) 1996 SAGE Publications London, Thousand Oaks and New Delhi, Vol 1(3) 307-322

\section{Abstract}

Patients and health-care providers bring a number of expectations to the medical encounter. Relational expectations are especially salient in this context given the emphasis placed on the need for effective communication. Relational expectations vary from one patient to the next and can vary widely among healthcare professionals. These expectations are based on an individual's past history of similar relationships and a perception of current conditions. The purpose of this work is to advance a model of relational expectations based on the cognitive and affective processes that function before and during the communication interaction. A conceptual analysis will synthesize previous work, culminating in the construction of a theoretical model of relational expectations. Further, implications of relational expectations will be noted as they affect the relationship quality, communication patterns and health outcomes of both patients and providers.

\section{Keywords}

affective processes, cognitive processes, expectations, interpersonal communication, provider-patient relationship 
A SUBSTANTIAL BODY of literature exists supporting the notion that communicators form general and specific expectations about interactions with others. Previous research substantiates that forming expectations plays a fundamental role in how human interaction is structured, perceived, evaluated, aligned and negotiated. Understanding the cognitive and affective expectations that patients and providers bring to the therapeutic context is a precursor to understanding the relationship between the psychological and communication properties of this unique interpersonal relationship. This article identifies the critical cognitive and affective components of expectations that patients and providers bring to the therapeutic context. The Relational Expectations Model is presented to illustrate how health-care delivery is negotiated. The model serves to explain how cognitive processes such as scripts, scenes, relational schemata and the like form relational expectations.

\section{Forming expectations}

\section{Relational knowledge}

The anticipation of interaction with someone else invokes cognitive processes that search for memory structures which develop representations approximating the expected communication episode. Depending on the anticipated interaction, relational knowledge may be highly structured containing vivid details based on previous experiences, perceptions of roles, existing belief structures, emotional memory and other elements of the persona that affect perceptual cognition. In the case of many health-care consumer-provider relationships, relational knowledge is assumed to be well-formulated and expectations are likely to be specific and resistant to change. On the other hand, anticipated interactions may not bring forth a level of relational knowledge that is well-formulated. If an individual has few experiences in a particular communication context or has experienced a wide range of disparate circumstances and outcomes, relational knowledge may be vague or uncertain. Expectations in this situation are more likely influenced by situational or generalized information emanating from the context.

Relational knowledge is assumed to exist in multiple layers within knowledge structures
(Kellerman, 1995). These layers may vary according to their level of abstractness and in the types of association and event that are related to particular relationships. For example, relational knowledge can exist at a general level of relationship type (e.g. physician, patient), at a more specific level of specific relationships (e.g. the relationship I have with my patients, with my physician) or at a level pertaining to a specific person (e.g. Dr Jones, Mr Craddock, self). These layers or levels of relational knowledge can overlap during cognitive processing to influence the planning for, and conduct of, social interaction. In the framework presented here (the Relational Expectations Model), relational knowledge serves as the basis for generating cognitive and affective processes that precede interaction. Figure 1 illustrates the model in graphic form.

\section{Scenes and scripts}

Relational knowledge is a general depiction of how information (e.g. memory, beliefs, goals) is organized for use in planning and conducting interaction. Specific components of relational knowledge have been identified that hold relational information. Kellerman (1995) is a proponent of dynamic-memory theory which assumes that memory is constantly changing in response to experiences. "Changes in memory occur by creating, altering, and updating scenes, the building blocks of memory. A scene is a grouping of generalized actions with shared salient goals; it is a collection of events whose common features have been abstracted' (Kellerman, 1995, p. 183). For example, patients develop scenes of dealing with office personnel in the waiting room of a physician's office. Not all physicians' offices and personnel are the same, but the general abstraction of this scene provides a fairly consistent and general memory of what it is like to be in this context. Similarly, health-care providers may develop scenes about convincing patients to follow a treatment regimen.

Related to scenes are scripts. A script is prior knowledge about something. 'At a very general level, a ... script consists of standard roles, props or objects, conditions and results' (Reed, 1988, p. 233). A script can be general information, so common that in some cases the script may be shared with other people. Therefore, if someone 


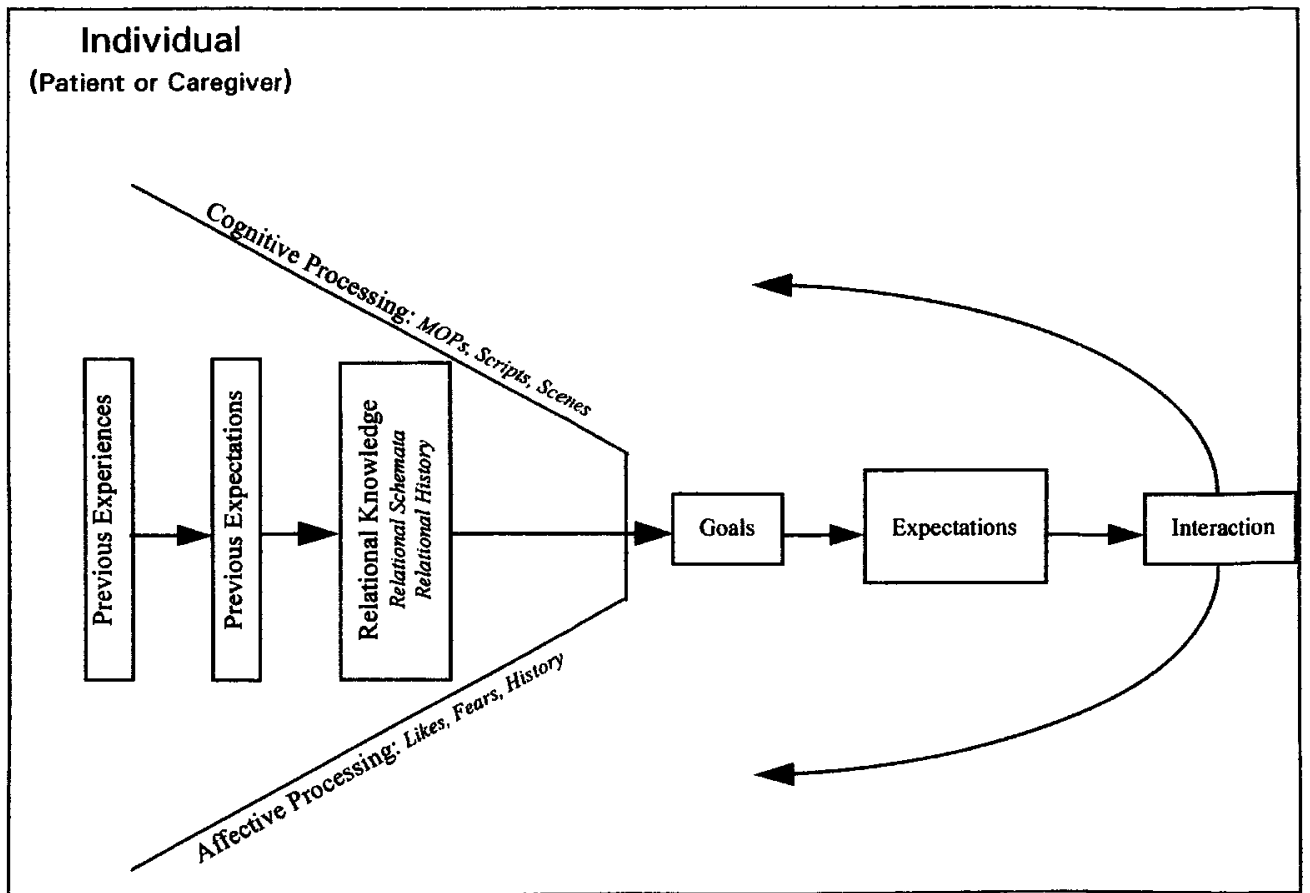

Figure 1: The Relational Expectations Model.

asked how your trip to the doctor's office was, there would be no need to describe the waiting room, the examining room or the doctor's performance, unless these actions violated a standard norm (perhaps an overly luxurious waiting room, excessively long waiting times or an unusual procedure). Scripts may also be very situationspecific, representing certain actions that provide detail for the scene. In other words, scenes contain scripts which offer a more detailed and precise means of thinking about events.

Bower, Black and Turner (1979) investigated the amount of agreement among subjects in various routine interactions. They asked participants $(n=24)$ to list approximately 20 actions or events which typically take place during a trip to the doctor's office, and other routine events. They found considerable agreement (split-half reliability $=.80$ ). Their results appear below (Table 1), where boldface letters denote items mentioned by the most people (55-75 percent agreement), items in italics by fewer subjects (40-50 percent), and items in regular type text by the fewest subjects (at least 25 percent agreement).
Table 1: Bower, Black and Turner's (1979) script for visiting a doctor

Enter office

Check in with receptionist

Sit down

Wait

Look at other people

Read magazine

Name called

Follow nurse

Enter exam room

Undress

Sit on table

Talk to nurse

Nurse tests

Wait

Doctor enters

Doctor greets

Talk to doctor about problem

Doctor asks questions

Doctor examines

Get dressed

Get medicine

Make another appointment

Leave office 
One can see the general agreement of the sequence of events (a script) which constitutes a doctor's office visit. The script itself is multipurposed. First, it is present when the events are taking place which cues the individual if there is a violation of a norm, expected event, or goalsometimes referred to as obstacles or distractions (i.e. Schank \& Abelson, 1977), expectancy violations (Burgoon, 1978; Burgoon \& Hale, 1988), or goal/planning disruption (Berger, 1995). Second, the script is also present during the reconstruction of the scene. As can be observed from the model, relational knowledge is drawn upon in the construction of scripts and scenes.

\section{Memory organization packets (MOPs)}

At a more global level, memory is structured by arranging or organizing a set of scenes that contribute to an overall goal. 'Scripts define a sequence of actions within scenes. An ordered array of scenes constitutes a memory organization packet (MOP) that serves the function of arranging plans for goal accomplishment. MOPs represent the specific constellation of scriptsubsuming scenes that identify various memory structures' (Honeycutt, Cantrill, \& Allen, 1992, p. 530). MOPs function as an assimilation device designed to arrange specific instrumental goals (found within scenes) into a higher order, more complex goal (Kellerman, 1995). A patient will develop an MOP about going to a laboratory for blood tests. General scenes about completing paperwork, having blood withdrawn and interacting with a lab technician are ordered into an array that produces the goal of complying with a request for a blood test. If during an actual episode, some aspect of the situation deviates from what is expected and driven by the MOP, scenes and MOPs are updated with the new information.

Although Kellerman (1995) argues for the existence of three classes of MOPs (physical, societal and personal), our purposes are best served in this discussion by not distinguishing among the classes but acknowledging that multiple MOPs of different types can be developed simultaneously in anticipation of interaction. Co-occurring multiple MOPs may overlap (Kellerman, 1995), creating alternative descriptions of anticipated interaction. MOPs serve the important function of providing cognitive struc- ture for the anticipatory stage of planned interaction. As the model illustrates, MOPs sequentially follow the organization of scripts and scenes and precipitate the development of goals and plans.

\section{Goals and plans}

MOPs lay the groundwork for developing goals and plans for social interaction. According to Berger (1995, p. 143), 'goals are desired end states toward which persons strive.' Patients develop goals for interaction with health-care providers that range from specific communication tactics (e.g. 'I will get her to renew my prescription.') to general communication strategies ('I hope he will spend enough time with me during the exam.'). Health-care providers function similarly by employing specific and generalized goals depending on the context. Caregivers utilize their training to diagnose medical conditions in a reductionistic manner with the goal of improving the patient's health-related quality of life by finding solutions for the specific cause of the patient's condition (Street, Gold, \& McDowell, 1995). Goals provide intent for social interaction and serve to put plans into place. Obviously patients and providers may develop multiple goals for any particular social interaction, and some of these goals may be more implicit (and even more subconscious) than others.

Plans constitute the organizing framework of actions that are necessary to accomplish goals (Berger, 1995). Although plans are devised based on goals, they do not always appear in the form of specific stratagem. Some plans are abstract and therefore are more flexible once interaction takes place. For instance, a patient may develop a plan that is broadly constructed around the goal of establishing effective interpersonal relations with the medical office staff. As interaction ensues, the patient can adapt according to the dynamics of the situation. Obviously, abstract plans provide less structure than do specific ones and would be more susceptible to the plans promulgated by interactional partners. Abstract plans also include the luxury of flexibility and adaptation, whereas highly specific plans would appear more like game plans where moves, plays and countermoves are anticipated.

When individuals are faced with the opportu- 
nity to devise a plan for social interaction, a first instinct is to search their memories for scripts that contain goals and plans pertaining to previously enacted or hypothesized interactions (Berger, 1995). The tendency to employ old plans rather than formulating new ones makes intuitive sense for several reasons. First, the ability to work from a preformulated template rather than beginning from scratch is a more efficient use of cognitive effort. Second, previous plans may have met with success suggesting that goal attainment could be achieved in a similar manner. Third, situational arousal and/or elevated cognitive load may lead an actor to seek familiar cognitive territory to cope more effectively with the situation. A likely scenario is one where a person retrieves an old plan and adapts it according to the parameters of the anticipated situation.

\section{Generating relational expectations}

Expectations not only serve the purpose of making plans more tangible but also serve as a conduit between plans and interaction. Expectations guide goal-driven plans toward an anticipated end result, and, therefore, expectations influence communication behavior in a direct way. Although not all expectations are reflected in behavior (some are simply not played out), and not all behavior is expectation-directed (spontaneous behavior), expectations do play a large role in how interaction is structured and negotiated. In addition to plans as an impetus for generating expectations, other cognitive structures are likely to influence the formation of relational or situation expectations.

One of the largest bodies of literature regarding the influence of expectations on interaction is that of categorization. One of the frequently recurring themes of this categorization literature is the complex cognitive process of stereotyping (e.g. Allport, 1979; Devine, 1989; Devine, Monteith, Zuwerink, \& Elliot, 1991; Hummert, Shaner, \& Garstka, 1994). The formation of the stereotype or strict adherence to a preconceived script may indeed effect the dynamics of the patient-caregiver interaction.

Humans organize their thoughts, emotions, beliefs and experiences with objects into rough categories, sometimes referred to as a 'schema' (Myers, 1990). Schemata are formed both for concrete objects and for social groups. The former poses utility in that it allows for analogous learning and prepares both patient and caregiver to react by learning from past experiences. For instance, a caregiver may learn that a common flu virus produces symptoms analogous to pneumonia. When a patient exhibits these symptoms, it is reasonable for the caregiver to form expectations that the patient is suffering from the common flu, and not necessarily pneumonia. Similarly, if you were to visit a doctor who was recommended by a friend as a 'good' caregiver, you may have some preconceived expectations that the caregiver's behavior would exceed your standard caregiverpatient script, based on your belief that the caregiver is 'good'. This preconceived belief may govern your expectations of the caregiver's performance. Actual performance would then be compared with the expectations of the interaction. The confirmation of the expected script behaviors reinforces the stability of the script.

Additionally, belief structures are likely to influence the formation of expectations. This is particularly true for situations involving healthcare delivery. In her meta-analysis of medical models, Perry (1993) provides an overview of 17 different models, each with a focus on provider dominance, patient dominance or mutually symmetrical participation. Among the four traditional models are the Sick Role Model (Parsons, 1951), the Balint Model (Balint, 1957), the Biopsychosocial Model (Engel, 1978) and the Health Belief Model (Becker, 1976).

Parsons' Sick Role Model states that patients should assume the role of a sick person, with the physician playing a paternalistic/maternalistic role. Also known as the Medical Model, this asymmetrical relationship is the model that was traditionally taught by most medical schools. Physicians' medical expertise is behaviorally reinforced as they are taught to assume the dominant role while patients are to assume a subordinate role.

The Balint Model recognizes the ongoing relationship between provider and patient and that the interaction will be situation specific. For example, the nature of the illness and the duration of the relationship both will influence the interaction. New relationships or short-term consultations will be less symmetrical, while established relationships or illnesses of a chronic 
nature will encompass more provider-patient symmetry.

Engel's Biopsychosocial Model is approached from a systems perspective whereby the patient is viewed as a whole entity that can be impacted from the subcellular level to a societal level, and disruption at any level can bring about illness. Rather than viewing the etiology of the disease from biological factors alone, psychosocial concerns are included in the conceptualization of the disease. Although this model addresses outside factors, the physician, though open to collaboration, still assumes a paternalistic/ maternalistic role in the interaction.

The Health Belief Model views patients as basically responsible for their own health. Thus, the physician recognizes the patient as an active participant in his or her health care. The patient's perceptions of the illness and the beliefs that she or he brings into the interaction significantly influence the method of treatment. In addition, factors such as the provider-patient relationship, prior experiences and social variables affect the patient's costs/benefit analysis in assessing health advice.

Whichever model is at work in the interaction, both the provider and the patient bring previous experiences to the interaction, and previous experiences in a particular relational context can have a profound influence on expectations. Persons with limited experiences are less likely to develop specific expectations about relationships compared to those with a background in these relationships (Honeycutt \& Cantrill, 1991). For example, Honeycutt, Cantrill and Allen (1992) found that people who had been in several relationships before were more likely to generate expectations for future relationships compared to those people who had developed very few or no relationships. Furthermore, a more extensive relational background was associated with faster cognitive retrieval of memory structures used to generate expectations (Honeycutt \& Cantrill, 1991; Honeycutt et al., 1992). It is expected that persons with a limited relational background will have to depend on cultural stereotypes or stereotypical roles as a means for generating expectations.

\section{Role-oriented relational expectations} Most scholars in the relational communication area assume that in the absence of specific relational knowledge about a partner or situation, a person must rely on information associated with stereotypes and roles. Furthermore, when relying on general, more abstract plans, stereotypes and beliefs, individuals are more likely to produce relational expectations that are based on the roles taken by fellow interlocutors. Similar to the notion of universal scenes advanced by Kellerman (1995), role-oriented expectations are based on generic conceptualizations of the anticipated situation and the roles inherent in that context. Since specific expectations cannot be generated from roles, behaviors will follow a more culturally prescribed path. Role-oriented communication will be the norm. Patients who have little experience with particular health-care providers will most likely formulate expectations based on the roles that are usually assumed by people in similar positions (Kreps, 1988). For instance, a patient who has been referred to a specialist by her or his family practitioner, and who has never been to a specialist, will generate expectations based on the roles played by previous physicians. These roles will be called up in the form of scripts and the communication behaviors expected will be generated by role-oriented MOPs.

In addition to occupational roles such as patient or caregiver, other roles recognized by society will come into play during the formation of relational expectations. Gender, socio-economic status, age and even physical appearance can influence the plans and expectations of relational partners (Kreps \& Kunimoto, 1994). For example, the fact that a physician is female will create different relational and communication expectations than if the physician is male (Klingle \& Burgoon, 1995), and elderly patients generate different expectations among caregivers than do children or adult patients ( $O^{\prime}$ Hair \& McNeilis, 1993). It is quite likely that physicians from different cultures will generate relational and communication expectations that are different from physicians who share the same cultural background with a patient.

Person-specific relational expectations Quite often, persons will have specific relational knowledge, person specific knowledge or what is known as relational history of a particular individual. Relational history will be retrieved from memory, and MOPs will be constructed 
based on previous interactions with that individual. Goals and plans will be tailored in a more definitive manner. Relational expectations in this case will be more structured and detailed, with greater confidence in their fulfillment. Ensuing interaction based on these expectations will carry a greater degree of predictability about the other person and the relationship. A patient who anticipates an appointment with a familiar and trusted physician will generate expectations that predict interaction sequences of a similar nature. Even specific styles of communication (verbal strategies, non-verbal behavior) are likely to be expected in this type of situation.

\section{Assumptions about patient expectations}

Thus far we have set the stage for revealing how expectations are formed in anticipation of social interaction. Based on previous literature, we can make some assumptions about the expectations that patients may develop about interactions with health-care providers, particularly physicians. Most individuals have prior relational experience with caregivers. This relational history, as we have mentioned, acts as a formative agent for relational and communicative expectations. However, unlike other relationships with a history, patients must negotiate their expectations within the context of the health-care delivery system which is often perceived as intimidating, uninviting, cold and sterile. Therefore, relational and communicative expectations are tempered by the situation and context. Expectations, especially of roles, can also evolve through the course of interaction. As McNeilis, Thompson, and O'Hair (1995) point out, 'physicians and patients are exchanging messages to reveal the nature of the medical condition, negotiate the treatment plan, and establish a relationship that is mutually negotiated. Traditional roles will often give way to negotiated roles that transpire from interaction' (p. 291).

Previous research indicates that patients prefer certain styles of communication and that their preferences are actually expectations (O'Hair, 1982). Most patients prefer caregiver communication that is affectively positive (O'Hair, 1986), especially younger and older patients (O'Hair, Behnke, \& King, 1983). Most adults prefer and expect caregiver communica- tion that contains a high level of information (O'Hair, et al., 1983). In general, patients expect a communication style that contains both psychosocial and informative elements. Whereas the caregiver's principal concerns center on bodily functions, the patient's principal concerns may involve other social and psychological aspects of health (Street et al., 1995).

Non-verbal behaviors will play an important role in the generation of expectations. Most patients appear to expect and prefer caregiver behavior that is moderately involved (normative levels of immediacy, expressiveness and proxemic distance) and vocalic patterns that are neutral to pleasant in nature (LePoire \& Parrott, 1988, 1989). Physicians demonstrating highly involved non-verbal patterns or behaviors that communicate low involvement would likely violate patient expectations (LePoire \& Burgoon, 1994).

In addition to the content elements of communication, some patients will form expectations about the relational components of communication messages. Relational communication refers to the means by which communicators reciprocally define their relationship. Communicators define their relationships by the types of message they expect and actually send to their partner. Of the three aspects of relational communication (control, trust and intimacy), relational control receives the most attention in the patient-provider literature. Communicators exert control over relationships by sending messages that define, direct and often dominate the relationship. How do patients exert control over their relationships with caregivers? Message-control techniques include those that are confrontational, question authority, make assertions, disconfirm, change topics, initiate or terminate interactions and provide instruction or answers to inquiries (O'Hair, 1989). Relational control techniques that allow definition or control of the relationship include supporting types of messages, asking questions and providing approval and confirmation. For the most part, patients communicate a low-to-moderate style of relational control (McNeilis \& Thompson, 1995; O'Hair, 1989; Von Friederichs-Fitzwater, Callahan, Flynn, \& Williams, 1991), except in instances when they are acting as an advocate for another patient such as a daughter or mother (O’Hair, 1989; O’Hair \& McNeilis, 1993). 
Assumptions about provider expectations Not only do patients enter into the physician-patient encounter with given expectations about the interaction, but physicians also bring their own expectations into the interpersonal exchange. However, physicians are taught the mechanics of the medical interview through their medical school training and, consequently, are afforded an advantage in the exchange. Most patients have only their personal experiences or vicarious experiences (as related by others) on which to base their expectations. For example, it is unusual to find a patient who has been taught relational control techniques specific to the medical setting.

Another prevailing assumption among both patients and physicians is that physicians are expected to exert authoritative control over the relationship and patients are expected to accept control (Ragan, Beck, \& White, 1995; Smith, 1992). Street, Gold and McDowell state 'although patients may ask questions and express their concerns, doctors typically control (and are allowed to control) the visit by initiating most of the discussion topics, interrupting to ask questions, offering opinions, directing the patient through the physician examination, and prescribing a course of action for the patient to follow' (p. 211). Compared to physicians, patients take a broader perspective to their health and well-being. Patients are more likely to relate health issues to the psychological and social aspects of their lives, and they consider the effects of health on important aspects of their lives such as work, family, recreation and other normal activities (Levenstein et al., 1989; Street et al., 1995). The social structure of medicine is largely responsible for the expectations that both physicians and patients have about their respective roles and the resulting imbalance in relational control.

Only as US society shifted from an agrarian society to that of an industrialized one did medicine move from folk and home remedies to the highly technical science that prevails today (Starr, 1982). Physicians' training became standardized as technological advances increased, eventually requiring licensing. According to Starr (1982), standardized education and licensing, in combination with patients' dependency on physicians' expertise, has given a definite structure to the relations of doctors and patients that transcends personalities and attitudes. This social structure is based, not purely on shared expectations about the roles of physicians and the sick, but on the institutionalized arrangements that often impose severe costs on people who wish to behave in some other way. (pp. 20-21)

In addition to the expectations about authority and roles that have been promulgated by society and medical training, physicians bring other expectations with them into the physicianpatient encounter. These expectations include assumptions about time, patients' competence, wishes and decision-making as well as expectations regarding what constitutes a 'good' patient.

Because medicine is a market-based commodity (Starr, 1982), physicians can afford to spend only a given amount of time with each patient. Therefore, physicians expect patients to make the visit as succinct as possible and not turn it into a social foray.

Relative to competence, physicians expect patients to possess fundamental, rudimentary medical knowledge. For example, Gorovitz (1982) relates a story of a woman who gave birth to a critically ill baby. When he told the mother that the baby 'did not make it' and asked for her permission to do an autopsy, she said okay and signed the necessary forms. When the doctor visited her the next day, she asked how her baby was and if the autopsy helped. She obviously had not understood the euphemism 'did not make it' and did not know what an autopsy was. Furthermore, a study by Guttman (1993) found a gap between what practitioners think their patients know and what they actually know about their health care.

Because of increased concerns about medical malpractice, physicians are moving more toward involving their patients in the decision-making process regarding treatment. Therefore, physicians expect patients to be honest and cooperative and provide all pertinent information so they can make accurate diagnoses, assess all available alternatives and minimize medical errors (Gorovitz, 1982). In addition, given that patients can be kept alive mechanically, often for an indefinite amount of time, physicians expect that patients will make their wishes 
known relative to treatment and end-of-life decisions (Cousins, 1988).

Each medical encounter is as varied as are the patients themselves. However, because of this variation, physicians have an expectation of what constitutes a 'good' patient. Although consensus is that 'good' patients comply with the treatment plan, other qualities include placing no excessive demands on medical staff and having a pleasant disposition (Day, 1992; Gorovitz, 1982).

Because patients are so varied, individual characteristics can affect physicians' expectations. Roter and Hall (1992) specify several characteristics or stereotypes that have the potential of affecting physicians' expectations about patients, including age, gender, social class, ethnicity or culture, physical appearance and attitude. Studies show that each of these factors contributes in some way to the physician-patient encounter (Beisecker \& Beisecker, 1990; Hooper, Comstock, Goodwin, \& Goodwin, 1982; Koopman, Eisenthal, \& Stoeckle, 1984; Roter 1991; Waitzkin, 1985).

\section{The effect of expectations on interaction}

Regardless of the number, valence and salience of expectations that patients and providers bring to the interaction, expectations have a direct influence on the messages that are sent and received. Taylor and Crocker (1981) report that expectations function as perceptual filters through which communicators evaluate messages. Although most of the research on relational expectations has focused on the receiver of messages (e.g. how messages are evaluated by targets), it stands to reason that expectations will guide the production of messages as well. Kellerman (1995), for example, argues that the number of scenes retrieved from memory to be used in a conversational episode are dependent on the expectations a communicator has about the length of the anticipated conversation. A physician who is running behind schedule may enact MOP that employs an abridged rapport building stage when interacting with a patient. Furthermore, given the relationship between plans and expectations, communicators will develop messages that conform to preformulated action sequences that are based on relational knowledge. The exact nature of these messages (content, relational) can take a turn at any point depending on whether expectations are confirmed or violated.

Based on research reviewed earlier, expectations of both patients and caregivers are likely to be well-formulated regardless of the level of role-oriented or person-specific attributions made in anticipation of the interaction. Monitoring for expected behavior will be engaged to confirm cognitive and affective predispositions based on relational knowledge processes. In some instances, the search for behaviors conforming to expectations may distract one from objectively observing behaviors that are unexpected or conceal verbal or non-verbal cues that lead to expectancy violation. In other instances, expectations are formed with the recognition that violations may occur during the interactional episode.

\section{The effect of interaction on expectations}

As patients and caregivers interact, the process of expectancy evaluation begins. At the risk of oversimplifying the process, communicators can choose from two alternative evaluation modes; they can decide that expectations were either confirmed or violated.

\section{Confirming expectations}

Expectations are confirmed when information from the environment, situation and fellow communicators conform to predispositions formulated by relational knowledge, MOPs, goals and plans. In spite of countervailing information or feedback that violates expectations, communicators may choose to ignore such information and focus exclusively on information that supports expectations. Consequently, expectations can be confirmed by accepting pro-expectancy feedback or by ignoring counter-expectancy feedback.

Accepting pro-expectancy feedback In the process of exchanging messages, patients and caregivers may accept or ignore the feedback they receive about their expectations. Not all information received and evaluated that fulfills relational expectations is accepted by communicators. When pro-expectancy feedback 
is accepted, it is based on two evaluation factors. First, is the information or feedback about expectations delivered in a sincere manner? If a patient feels that a caregiver is demonstrating immediacy behaviors as expected because that is her or his natural style, pro-expectancy feedback can be judged sincere. Second, pro-expectancy feedback is evaluated based on its plausibility. Does the immediacy behavior that was expected really make sense in this context or situation? In other words, when expected behavior is presented that seems reasonable for the communication context, expectations are satisfied. When plausibility and sincerity criteria are satisfied, pro-expectancy feedback will lead to a confirmation of expectations.

One caveat should be discussed regarding pro-expectancy feedback. Confirming expectations based on pro-expectancy feedback does not necessarily produce the type of communication that leads to good health care. Patients may feel that physicians are unable to improve their medical condition leading to expectations that are pessimistic and unrewarding. Observing physician behavior during the interaction that confirms their pessimism may cause a patient to withdraw and become less involved in the structure of conversation. In cases such as these, violations of expectations could break the pattern of pessimism and lead to a more productive pattern of communication (e.g. inquisitiveness, interrogation, etc.).

\section{Ignoring counter-expectancy feedback} Quite often a communicator will receive counter-expectancy feedback and choose to ignore it. Ignoring the type of information that would normally lead to expectancy violation is based on the same criteria previously described. In the first instance, counter-expectancy feedback may be judged as insincere. Patients who initially expect caregivers to demonstrate a caring and supportive manner only to observe the physician as cold and aloof may choose to ignore this information as being a strategy employed by the caregiver for a specific purpose. The patient may infer, for example, that the caregiver is acting in a counter-expectancy manner to call attention to the seriousness of the situation, thereby demonstrating care and support, albeit in a strategic way. Violation of sincerity criteria invalidates the counter-expect- ancy information, causing the patient to ignore some of this feedback. Or, consider the example of a caregiver who observes a cooperative demeanor from a patient who is typically (and expectedly) recalcitrant during treatment. Although a normal reaction may be to evaluate this information as counter-expectancy feedback, based on previous behavior and detection of non-verbal cues, the caregiver concludes that the patient is being cooperative to avoid additional treatment episodes.

Additionally, a patient may see counterexpectancy information as implausible for the situation and discount it. Using the same example, we see that if a patient observes a caregiver who is cold and aloof (which is contrary to her or his normative and expected behavior), the patient may simply attribute this data to external conditions ('she is having a bad day, it has nothing to do with me') that have no relevance for the present relationship. In other words, counter-expectancy feedback is not viewed as plausible in this case and the information is ignored, causing the original expectations to remain intact.

\section{Reacting to confirmed expectations}

When expectations are confirmed, either retrospectively or on-line, a number of cognitive processes are engaged. First, although the confirmation of expectations is not believed to be a highly arousing event (unlike expectancy violation), some low level of arousal is likely to be initiated leading to neutral or positive affective evaluation of the communication episode. As a result, relational knowledge is verified and thereby strengthened. The resulting authentication of employed scripts, scenes and MOPs are reinforced and primed for utilization in future episodes of a similar nature. The level of confidence will increase for developing expectations of this type.

Beyond the corroboration of scripts and MOPs and the verification of relational knowledge, confirmation of expectations will also act as a motivating force for moving plans and goals forward. Patients and caregivers will continue the process of unpacking the components of plans that are based on the goals for interaction. Original plans may even become more ambitious if communicators have confidence that anticipated and spontaneous expectations can be 
met by their relational partners. For instance, after having her or his expectations met by a physical therapist (therapist was communicatively open and inquisitive), a patient may revise an original plan of simply following treatment regimen by asking for a higher level of treatment involvement. Goals and plans can be adjusted, on-line, based on the confirmation of expectations.

\section{Violating expectations}

Quite often verbal and non-verbal behavioral expectations are violated by a relational partner. At the most simplistic level, two alternative explanations are available for determining the cause of expectancy violation: Either the formulated expectations were unrealistic, precipitated by a number of cognitive and affective factors (e.g. inaccurate or incomplete relational history, emotional interference, faulty scripts, poorly designed MOPs, etc.); or a relational partner behaves in a manner that is normatively inconsistent. Regardless of the explanation, the violation of expectations engages cognitive and affective processes that are heightened beyond normal patterns. As with the confirmation process, expectancy violations can be realized following the evaluation of pro-expectancy and counter-expectancy feedback.

Ignoring pro-expectancy feedback Based on the sincerity and plausibility principles previously outlined, communicators may choose to ignore information that could potentially confirm their expectations. First, pro-expectancy information may seem less than sincere, generating suspicious or cynical evaluations of the information. Communicators may find themselves in situations where the behavioral indicators of their relational partner conform to expectations, yet distrust the intentions and motivations underlying their partner's behaviors. A physician may expect a long-standing and familiar patient to behave in certain ways based on relational history only to observe this individual acting in ways normally expected, but out of step with the contextual or idiosyncratic features of the situation. The patient is being a good self-monitor (Snyder, 1974) producing normative behaviors expected to conform to cultural and situation expectations, the same expectations held by the physicians. However, certain cues reveal an insincere motive on the part of the patient. The physician's expectations are violated and cognitive and affective processes begin to search for explanations behind the expectancy violation. Communicators may also violate the implausibility criteria, by producing behaviors that conform to (unrealistic) expectations. In this case, expectations may be developed in the form of optimistic projections, and in the course of interaction these same expectations, although produced and observed, are obviously incongruent with the realistic parameters of the situation at hand. A patient may find the caregiver to exhibit highly involving and personalistic communication styles similar to those (optimistically) projected, yet at the same time the patient recognizes that this behavior is incongruent with that caregiver's normative style. This type of information may be ignored in favor of other information that is more situationally consistent.

Accepting counter-expectancy feedback It is hypothesized that recognizing and accepting counter-expectancy feedback is the most common form of expectancy violation. After applying sincerity and plausibility criteria and determining the validity of the information received and evaluated, a communicator is faced with the prospect that expectations have gone awry. Information received from the context and the relational partner will often lead to the conclusion that expectations, even those of a normative nature, have been violated, and at this point, a heightened level of cognitive and affective processes are engaged to account for the 'error in judgment' apparent in the expectancy formation process. The processes employed to account for expectancy violation are multifunctional and constitute a global quest to reduce uncertainty created by the behavioral unexpectancies introduced by one's relational partner.

\section{Reacting to expectancy violations}

Notwithstanding the importance of accurately observing expectancy violations, the most salient component of this model is the reaction to behavioral unexpectancies. As mentioned previously, multiple processes are invoked to account for expectancy violation. According to Burgoon and Hale (1988), arousal is the first response following a demonstration of behaviors 
falling outside of the levels of expectancy. Primarily based within the cognitive domain, the experience of arousal creates 'an alertness or orienting response that diverts attention away from the ostensive purpose of the interaction and focuses it toward the source of the arousal-the initiator of the violation' (p. 62). With arousal comes uncertainty about the relational partner and the relationship and a search for explanation is initiated, the intensity of which is dependent on the saliency of the relationship and the content of the interaction. Based on the information acquired during the search, relational knowledge can be updated.

Arousal/uncertainty Although the positive violation of expectations will induce a certain level of arousal in many people, the level of uncertainty associated with this event is unlikely to approach that of violations that are negative in nature. To simplify our discussion, we will focus primarily on negative violations of expectations. Communication behaviors that violate expectations create arousal, usually in the form of discomfort. This affective response will trigger or accompany uncertainty, which is the cognitive response to expectancy violation. The level of uncertainty about the situation and the relationship escalates based on the failed experience of generating expectations. A patient expecting a caregiver to respond to inquiries in an expected manner (direct eye contact, frontal body orientation, reduced proxemics) will experience elevated levels of arousal and uncertainty when the caregiver does not conform to expectations.

The intensity level of the arousal will affect the level of effort directed toward subsequent processes such as searching for explanations. Although Berger (1995) focused on goal and plan achievement, his explanation for how arousal is produced by the blockage of plans is analogous and applicable to arousal induced by expectancy violation. Arousal is influenced by (a) the importance of the expectation, (b) the psychological distance between expected and observed behaviors and (c) the level of investment made by the relational partner toward the interaction. Furthermore, as goals and plans are thwarted by the process of expectancy violation, arousal will elevate in relation to the importance of those plans.
The inducement of arousal brings about an interpretation of the behavior that represents unexpected behavior (LePoire \& Burgoon, 1994). Once the behavior is interpreted and confidence is placed on the accuracy of the interpretation, an evaluation process will ensue that accounts for why the expectancy process, primarily concerned with relational elements, was deemed inaccurate.

Search for explanations In most cases, patients will strive to reduce arousal and uncertainty by searching for information that explains the reasons for the failed expectations (Planalp \& Rivers, 1988; Schank, Collins, \& Hunter, 1986). Two methods are available to reduce uncertainty caused by failed expectations. First, communicators can confront their relational partners in an attempt to ascertain directly the causes for the behavior that violate expectations ('Why aren't you going to be with me for the treatment?'). The second method, and probably the most common, is to re-examine the original memory structures that constitute relational knowledge. Patients and caregivers are likely to make the following inquiries in an attempt to close the gap between previous relational knowledge and the failed expectation:

- What aspects of relational knowledge were lacking or erroneous?

- In what ways was relational knowledge inappropriately applied?

- What role did scripts, scenes and MOPs play in the failed expectation?

- Did some level of affect interfere with the generation of expectations?

- Were the goals/plans too ambitious and unrealistic?

The cognitive and affective search processes involved in this procedure may not always produce the level or type of data that satisfies the impetus for the search for explanation.

Updating relational knowledge Determining answers to these questions provides an opportunity to explain how expectations were violated by relational partners (i.e. uncertainty reduction). As conclusions are drawn about the nature of the failed expectations, relational knowledge can be updated. According to Kellerman (1995), 'updating occurs when sufficient 
reason exists to modify, replace, and/or reorganize parts of memory' (p. 203). As relational knowledge is updated, arousal and uncertainty can be reduced, and a revised memory structure is now available to generate new scripts and scenes leading to reformulated MOPs to be used in social interaction. Updating relational knowledge is a learning process whereby expectancy violations lead to a search for information that can reduce uncertainty and generate revised expectations for ongoing and future interaction (Kellerman, 1995; Planalp \& Rivers, 1988; Schank et al., 1986).

\section{Managing interaction}

The ability of a patient or provider to engage in meaningful interaction after expectancy violation is contingent on how a reformulated base of relational knowledge is handled. In spite of new information that modifies scripts and scenes associated with this relationship, communicators may choose to pursue their original plans in the face of expectancy violations. On the other hand, a revised form of relational knowledge may produce an adjustment in MOPS, goals and plans during an interactional episode.

Pursuing original plans Some patients and caregivers may pursue their original plans even in the face of expectancy violations. Undaunted by a failure to produce fulfilled expectations, communicators may find their original goals and plans so important that it would be unwise to alter their course of action (e.g. could lead to goal blockage, interpersonal conflict, etc.). Instead, alteration of plans at their more fundamental levels can be made. According to Berger (1995), 'when goal-directed actions are thwarted, and individuals continue to pursue the goals in question, their first tendency is to alter low-level plan elements, rather than more abstract plan elements, because such modifications require fewer cognitive resources for their implementation' (p. 161). For example, an oncologist may find that her or his expectations were violated when she or he anticipated a cancer patient to accommodate her or his more aggressive tactics of persuasion regarding treatment adherence. Instead of adopting a new action plan, the oncologist adjusts the lower level components of her or his plan by restating the prescriptive strategy in a more emphatic tone.
On-line adjustment of expectations, plans, and behaviors Many communicators will make on-line adjustments of their expectations, plans and behaviors grounded in updated relational knowledge structures. Based on a heightened level of arousal and a subsequent search for explanations, providers and patients may find adaptation as an optimal alternative. For example, LePoire and Burgoon (1994) discovered that when patients observed (confederate) physicians to deviate from normative involvement levels, patients adjusted their own level of involvement behavior as a response mechanism. At the cognitive level, modified expectations may be based on a more flexible and cautious planning structure allowing for greater latitude in received and produced communication behaviors.

\section{Implications of the model}

The model presented here depicts a process of relational expectation formation, with implications for the provider-patient relationship as suggested at various points during the discussion. One of the key features of the model involves expectancy violations. Most of the research involving relational and communicative expectations specific to the provider-patient context has focused on this phase of the model. Clearly, a basic assumption resulting from this area of research states that relational dissatisfaction ensues from negative expectancy violations (Burgoon, Birk, \& Hall, 1991; Klingle \& Burgoon, 1995; LePoire \& Burgoon, 1994). In contrast, positively viewed expectancy violations can produce satisfactory perceptions of the relationship. In fact, according to Klingle and Burgoon, inconsistent or alternating message strategies communicated by physicians may be more persuasive than the use of a single strategy even when this strategy is thought to be most preferred by patients. In other words, expectancy violations serve to get the attention of the patient with the ultimate goal of inducing a change in behavior.

The Relational Expectations Model we have suggested is expected to generate additional discussion in the provider-patient context. Future research should address some of the following areas that would serve to explicate and extend the model. 
To what extent is it the responsibility of caregivers to confirm expectations? and To what extent should caregivers take into consideration the pre-existing relational knowledge and expectations of the patient? Such considerations may indeed impact the structure of the interaction.

Also, how stable is the strategy of violating expectations for persuasive purposes? and In which health-care context are our strategies more malleable? The role of 'caregiver' may blur with the rise in popularity of HMOs, and non-traditional therapies. Research should investigate the change in communication styles and strategies within these new contexts.

Finally, how can caregivers and patients develop stronger relational knowledge to produce more realistic expectations? and Will such strategies ultimately benefit the treatment of the patient? What other outcome variables (other than improved treatment) stem from interaction? Is patient satisfaction important? Is caregiver satisfaction important?

How do related psychological concepts like Festinger's cognitive dissonance theory relate to violations of expectations? How do caregiver assumptions about patient expectations influence interaction (e.g. if a physician assumes a patient wants to reduce his or her back pain, when in reality the patient wants to remain ill and continue to receive worker's compensation)? What are the implications of such assumptions for future interaction?

The concept of the Relational Expectations Model is fundamentally simple in design, yet has multiple constructs and variables which may impact its linearity. We believe this area of investigation is rich for future research.

\section{References and further reading}

Allport, G. W. (1979). The nature of prejudice. Reading, MA: Addison-Wesley.

Ashforth, B. E., \& Mael, F. (1989). Social identity theory and the organization. Academy of Management Review, 14, 20-39.

Ashmore, R. D., \& Del Boca, F. K. (1981). Conceptual approaches to stereotypes and stereotyping. In D. L. Hamilton (Ed.), Cognitive processes in stereotyping and intergroup behavior (pp. 1-35). Hillsdale, NJ: Erlbaum.

Balint, M. (1957). The doctor, his patient and the illness. London: Pitman Medical.
Becker, M. H. (1976). Sociobehavioral determinants of compliance. In D. L. Sackett \& R. B. Haynes (Eds.), Compliance with therapeutic regimens (pp. 40-50). Baltimore, MD: Johns Hopkins University Press.

Beisecker, A. E., \& Beisecker, T. D. (1990). Patient information-seeking behaviors when communicating with doctors. Medical Care, 28, 19-28.

Berger, C. (1995). A plan-based approach to strategic communication. In D. Hewes (Ed.), The cognitive bases of interpersonal communication ( $\mathrm{pp}$. 141-179). Hillsdale, NJ: Erlbaum.

Bower, G. H., Black, J. B., \& Turner, T. J. (1979). Scripts in memory for text. Cognitive Psychology, $11,177-220$.

Burgoon, J. K. (1978). A communication model of personal space violations: Explication and an initial test. Human Communication Research, 4, 129-142.

Burgoon, J. K., \& Hale, J. L. (1988). Nonverbal expectancy violations: Model elaboration and application to immediacy behaviors. Communication Monographs, 55, 58-79.

Burgoon, M., Birk, T. S., \& Hall, J. R. (1991). Compliance and satisfaction with physicianpatient communication: An expectancy theory interpretation of gender differences. Human Communication Research, 18, 177-208.

Cousins, N. (1988). Intangibles in medicine: An attempt at balancing perspective. JAMA, 260, 1610-1612.

Day, T. W. (1992). Cross-cultural medicine at home. Minnesota Medicine, 75, 15-17.

Devine, P. G. (1989). Stereotypes and prejudice: Their automatic and controlled components. Journal of Personality and Social Psychology, 56, 5-18.

Devine, P. G., Monteith, M. J., Zuwerink, J. R., \& Elliot, A. J. (1991). Prejudice with and without compunction. Journal of Personality and Social Psychology, 60, 817-830.

Engel, G. L. (1978). The biopsychosocial model and the education of health professionals. Annals of the New York Academy of Sciences, 310, 169-181.

Gilbert, D. T., \& Hixon, J. G. (1991). The trouble of thinking: Activation and application of stereotypic beliefs. Journal of Personality and Social Psychology, 60, 509-517.

Gorovitz, S. (1982). Doctors' dilemmas: Moral confict and medical care. New York: Macmillan.

Greenwald, A. G. (1980). The totalitarian ego: Fabrication and revision of personal history. American Psychologist, 35, 603-618.

Guttman, N. (1993). Information exchange in medical encounters: Problems and promises. In B. D. Ruben \& N. Guttman (Eds.), Caregiver-patient 
communication: Readings (pp. 151-168).

Dubuque, IA: Kendall/Hunt.

Hamilton, D. L., \& Gifford, R. K. (1976). Illusory correlation in interpersonal perception: A cognitive basis of stereotypic judgments. Journal of Experimental Social Psychology, 12, 392-407.

Honeycutt, J. M., \& Cantrill, J. G. (1991). Using expectations of relational actions to predict number of intimate relationships: Don Juan and Romeo unmasked. Communication Reports, 4, 14-21.

Honeycutt, J.M., Cantrill, J.G., \& Allen, T. (1992). Memory structures for relational decay: A cognitive test of sequencing of de-escalation actions and stages. Human Communication Research, 18, 528-562.

Hooper, E. M., Comstock, L. M., Goodwin, J. M., \& Goodwin, J. S. (1982). Patient characteristics that influence physician behavior. Medical Care, 20, 630-638.

Hummert, M. L. (1990). Multiple stereotypes of elderly and young adults: A comparison of structure and evaluations. Psychology and Aging, 5, 182-193.

Hummert, M. L., Shaner, J. L., \& Garstka, T. A. (1994). Cognitive processes affecting communication with older adults: The cases for stereotypes, attitudes and beliefs about communication. In J. F. Nussbaum \& J. Coupland (Eds.), Handbook of communication and aging research. Hillsdale, NJ: Erlbaum.

Kellerman, K. (1995). The conversation MOP: A model of patterned and pliable behavior. In $\mathrm{D}$. Hewes (Ed.), The cognitive bases of interpersonal communication (pp. 181-221). Hillsdale, NJ: Erlbaum.

Klingle, R. S., \& Burgoon, M. (1995). Patient compliance and satisfaction with physician influence attempts: A reinforcement expectancy approach to compliance-gaining over time. Communication Research, 22, 148-187.

Koopman, C. S., Eisenthal, S., \& Stoeckle, J. (1984). Ethnicity in the reported pain, emotional distress and requests of medical outpatients. Social Science \& Medicine, 6, 487-490.

Kreps, G. L. (1988). The pervasive role of information in health and health care: Implications for health communication policy. In J. A. Anderson (Ed.), Communication yearbook 11 (pp. 238-276). Newbury Park, CA: Sage.

Kreps, G. L., \& Kunimoto, E. N. (1994) Communicating effectively in health care contexts. Thousand Oaks, CA: Sage.

Kreps, G., O'Hair, D., \& Clowers, M. (1994). The influence of human communication on health outcomes. American Behavioral Scientist, 38, 248-256.
LePoire, B. A., \& Burgoon, J. K. (1994). Two contrasting explanations of involvement violations: Expectancy violations theory versus discrepancy arousal theory. Human Communication Research 20, 560-591.

LePoire, B. A., \& Parrott, R. (1988). Attributes of the credible pediatrician's voice. In D. O'Hair \& B. Patterson (Eds.), Advances in interpersonal communication research: Proceedings from the Western Speech Communication Association (pp. 91-105). Las Cruces, NM: Communication Resources Center.

LePoire, B. A., \& Parrott, R. (1989, May). Positive violations of relational communication expectations in health care. Paper presented at the International Communication Association convention, San Francisco, CA.

Levenstein, J. H., Brown, J. B., Weston, W. W., Stewart, M., McCracken, E. C., \& McWhinney, I. (1989). Patient-centered clinical interviewing. In M. Stewart \& D. Roter (Eds.), Communicating with medical patients (pp. 107-120). Newbury Park, CA: Sage.

McNeilis, K. S., \& Thompson, T. L. (1995). The impact of relational control on patient compliance in dentist-patient interactions. In G. Kreps \& D. O'Hair (Eds.), Communication and health outcomes (pp. 57-72). Cresskill, NJ: Hampton.

McNeilis, K. S., Thompson, T. L., \& O'Hair, D. (1995). Implications of relational communication for therapeutic discourse. In G. Morris, \& R. Chenail (Eds.), The talk of the clinic (pp. 291-313). Hillsdale, NJ: Erlbaum.

Myers, D. G. (1990). Social psychology. New York: McGraw-Hill.

O'Hair, D. (1986). Patient preferences for physician persuasion strategies. Theoretical Medicine, 7 , 147-164.

O'Hair, D. (1989). Dimensions of relational communication and control during physician and patient interactions. Health Communication, 1, 97-116.

O'Hair, D., Behnke, R., \& King, P. (1983). Agerelated patient preferences for physician communication behavior. Educational Gerontology, 9, 147-158.

O'Hair, D., \& McNeilis, K. (1993). Advocates for the elderly patient: A case of mutual influence. In E. B. Ray (Ed.), Case studies in health communication (pp. 61-73). Hillsdale, NJ: Erlbaum.

O'Hair, D., O'Hair, M., Southward, M., \& Krayer, K. (1987). Patient compliance and physician communication. Journal of Compliance in Health Care, 2, 125-128.

O'Hair, H. D. (1982). Patient preferences for physician communication behavior: An analysis of 
treatment compliance strategies. Doctoral dissertation, University of Oklahoma.

Parsons, T. (1951). The social system. New York: Free Press.

Perry, C. A. (1993). Models of physician-patient interaction: Paternalism to mutual participation. In B. D. Ruben \& N. Guttman (Eds.), Caregiverpatient communication: Readings (pp. 22-39). Dubuque, IA: Kendall/Hunt.

Planalp, S., \& Rivers, M. (1988). Changes in knowledge of relationships. Paper presented at the annual meeting of the International Communication Association, New Orleans, LA.

Ragan, S. L., Beck, C. S., \& White, M. D. (1995). Educating the patient: Interactive learning in an OB-GYN Context. In G. H. Morris \& R. L. Chenail (Eds.), The talk of the clinic (pp. 185-208). Hillsdale, NJ: Erlbaum.

Reed, S. K. (1988). Cognition: Theory and applications (2nd. ed.). Pacific Grove, CA: Brooks/Cole.

Roter, D. (1991). Elderly patient-physician communication: A descriptive study of content and affect during the medical encounter. Advances in Health Education, 3, 15-23.

Roter, D. L., \& Hall, J. A. (1992). Doctors talking with patients/patients talking with doctors: Improving communication in medical visits. Westport, CT: Auburn House.

Schank, R., \& Abelson, R. (1977). Scripts, goals, and understanding. Hillsdale, NJ: Erlbaum.
Schank, R. C., Collins, G. C., \& Hunter, L. E. (1986). Transcending inductive category formation in learning. Behavioral and Brain Science, 9, 639-686.

Smith, J. M. (1992). Women and doctors. New York: Atlantic Monthly.

Snyder, M. (1974). Self-monitoring and expressive behavior. Journal of Personality and Social Psychology, 30, 526-537.

Starr, P. (1982). The social transformation of American medicine. New York: Basic Books.

Street, R. L., Gold, W. R., \& McDowell, T. (1995). Discussing health-related quality of life in prenatal consultations. In G. H. Morris \& R. L. Chenail (Eds.), The talk of the clinic (pp. 209-231). Hillsdale, NJ: Erlbaum.

Tulving, E. (1972). Episodic and semantic memory. In E. Tulving \& W. Donaldson (Eds.), Organization and Memory. New York: Academic.

Taylor, S. E., \& Crocker, J. (1981). Schematic bases of social information processing. In E. T. Higgins, C. P. Herman, \& M. P. Zanna (Eds.), Social cognition: The Ontario symposium, volume I (pp. 89-134). Hillsdale, NJ: Erlbaum.

Von Friederichs-Fitzwater, M. M., Callahan, E. J., Flynn, N., \& Williams, J. (1991). Relational control in physician-patient encounters. Health Communication, 3, 17-36.

Waitzkin, H. (1985). Information giving in medical care. Journal of Health and Social Behavior, 26, 81-101. 